\title{
The influence of geometry on the stress distribution in joints - a finite element analysis
}

\author{
Felix Eckstein', Beat Merz ${ }^{2}$, Peter Schmid ${ }^{2}$, Reinhard Putz ${ }^{1}$ \\ ${ }^{1}$ Anatomische Anstalt der Ludwig Maximilians Universität München, Pettenkoferstrasse 11, D-80336 München, Germany \\ ${ }^{2}$ Institut für Biomedizinische Technik und Medizinische Informatik der ETH Zürich, ETH Zentrum, CH-8092 Zürich, Swizzerland
}

Accepted: 3 February 1994

\begin{abstract}
The incongruity of human joints is a phenomenon which has long been recognized, and recent CT-osteoabsorptiometric findings suggest that this incongruity influences the distribution of stress in joints during their normal physiological use. The finite element method (FEM) was therefore applied to five different geometric configurations consistent with the anatomy of articular surfaces, and a program with variable contact areas (Marc) was used to calculate the stress distribution for loads of 100 to $6900 \mathrm{~N}$. The assumption of congruity between head and socket results in a "bell-shaped" distribution of stress with a maximum value of $61.5 \mathrm{~N} / \mathrm{mm}^{2}$ in the depths of the socket, decreasing towards zero at its edges. In the model with a flatter socket the von Mises stresses are higher $\left(\max .101 .3 \mathrm{~N} / \mathrm{mm}^{2}\right)$; with a deeper socket, lower $\left(\max .53 .0 \mathrm{~N} / \mathrm{mm}^{2}\right)$. If the diameter of the head is greater, the stresses build up from the periphery of the socket and move towards its depths as the load increases. The combination of an oversized head and a deeper socket results in the most satisfactory stress distribution (max. $43.2 \mathrm{~N} / \mathrm{mm}^{2}$ ). These results extend previous photoelastic findings with incongruous joint surfaces. The calculated mechanical conditions show a relationship to the location of osteoarthritic changes, and are reflected by the distribution pattern of subchondral bone density. A more satisfactory stress distribution is found with functionally advantageous, incongruous joint surfaces (oversized head and deepened socket) than in the congruous joint, and a better nutritive situation for the articular cartilage seems likely. The geometry of the joint is therefore a physiologically important and quantifiable factor contributing to an optimized transmission of forces in joints.
\end{abstract}

Key words: Incongruity - Joint loading - Load distribution - Finite element method - Joint geometry

\section{Introduction}

$\mathrm{X}$-ray densitometry and the more recent investigations carried out with CT-osteoabsorptiometry on some larger joints of the human body have established that the incongruous shape of their components plays an important physiological role during the day-to-day use. This applies, for instance, to the hipjoint (Müller-Gerbl et al. 1993), the anklejoint (Müller-Gerbl and Putz 1993) and the humero-ulnar joint (Tillmann 1971, 1978; Eckstein et al. $1993 \mathrm{a}, \mathrm{b}$ ), in all of which - at least during youth - the joint socket is obviously deeper than would exactly fit the corresponding head. The reverse situation is found in the radiohumeral joint, where the subchondral mineralization pattern (Eckstein et al. 1993 a), the curvatures, and the contact areas (Bünck 1990) suggest a flatter socket in relation to the head.

The idea of a physiological incongruity within human joints is not at all new. The phenomenon has been qualitatively described for the hip by numerous investigators using several different methods of approach (Walmsley 1928; Bullough et al. 1968, 1973; Greenwald and O'Connor 1971; Day et al. 1975; Goodfellow and Mitsou 1977; Rushfeldt and Mann 1979; Afoke et al. 1980; Miyanaga et al. 1984; Löhe et al. 1993). There is also clear evidence that the components of the anklejoint do not make a perfect fit (Riede et al. 1971; Wynarsky and Greenwald 1983). Bullough and Jagannath (1983) observed the greater depth of the trochlear notch as compared with the trochlea itself in a sagittal section through the humero-ulnar joint. We have been able to confirm this geometric configuration during an investigation into the contact areas (Eckstein et al. 1993 b) and were able to quantify it as a function of the load applied by a casting method (Eckstein et al. $1993 \mathrm{c}$ ).

Investigations by Ingelmark and Ekholm (1948) have also given reason to believe that cartilage, at the beginning of its physiological activity, undergoes about 5 to $10 \%$ swelling. Basing their arguments on this hypothesis, Oberländer et al. (1984) suggested that, in joints in which one component widely encompasses the other (the 
humero-ulnar joint, for instance), this swelling leads to narrowing of the socket inlet. The head of the joint, which then becomes secondarily too large, is thus raised up out of the socket. This finding has not so far been confirmed by newer radiologic techniques, but the possibility remains that the head of the joint, either because of this functional swelling of the cartilage or because of its initial condition, is wider in diameter than its corresponding socket.

It is reasonable to suppose that the geometrical structure of the joint components directly affects the position and size of the load-bearing areas, and therefore the distribution of stress within the joint (Tillmann 1978; Mockenhaupt 1990; Soslowsky et al. 1992; Eckstein et al 1993 b). Bullough (1981) and Greenwald (1991) have developed a theoretical model for this, and have suggested that stress is more satisfactorily taken up by incongruous than by congruous joints when the sockets are deeper, but that the reverse is true when they are flatter.

Photoelastic models of the stress distribution in incongruous joints have been reported by Kempson et al. (1971 - hip-joint) and Tillmann (1978 - humero-ulnar joint). Unfortunately this technique can only provide a qualitative assessment of the stress distribution (Pauwels 1980; Orr 1992), and it is difficult to apply it to subtle geometric variations. As against this, quantitative values for almost any chosen structure can be calculated by using the finite element method (FEM - Huiskes and Chao 1983, Zienkiewicz and Taylor 1989). However, up to now this method has always been used with the assumption that the joint surfaces are congruous (Rapperport et al. 1985; Carter et al. 1987 a, Schröder and Gall 1992).

The purpose of this investigation is therefore to use the finite element method (FEM) in order to analyse the quantitative influence of the geometry of the joint on its stress distribution. Different geometrical shapes which include the described anatomical data will be used as a basis for this.

\section{Materials and methods}

Five models were considered, the fundamental geometrical properties of which are defined in Fig. 1. Model 1 (Fig. 2 a) is based on the congruity of hemispherical joint surfaces, with equal radii for both joint head and socket $\left(x^{\mathrm{p}}=y^{\mathrm{p}}=x^{\mathrm{k}}=y^{\mathrm{k}}=10.0 \mathrm{~mm}\right)$. Model 2 (Fig. 3 a) represents incongruity of the joint surfaces and reflects qualitatively the situation in the radiohumeral joint. The head is semicircular in vertical section, but the socket is semielliptical; the radius of the inlet is $2.5 \%$ greater than the radius of the head, whereas the depth of the socket is equal to the radius of the head $\left(x^{\mathrm{p}}=10.25 \mathrm{~mm}, y^{\mathrm{p}}=x^{\mathrm{k}}=y^{\mathrm{k}}=10.0 \mathrm{~mm}\right.$ ). Model 3 (Fig. 4 a) corresponds to an incongruous joint which qualitatively represents the characteristics of the hipjoint, anklejoint and humero-ulnar joint. In this case the entry into the elliptical socket has the same diameter as the head, although the depth of the socket is $2.5 \%$ greater than its radius $\left(y^{\mathrm{p}}=10.25 \mathrm{~mm},\left(x^{\mathrm{p}}=x^{\mathrm{k}}=y^{\mathrm{k}}=10.0 \mathrm{~mm}\right)\right.$. In model 4 (Fig. 5 a) both head and socket are hemispherical, the head having a diameter $1 \%$ greater than that of the socket $\left(x^{\mathrm{k}}=y^{\mathrm{k}}=10.1 \mathrm{~mm}\right.$, $x^{\mathrm{p}}=y^{\mathrm{p}}=10.0 \mathrm{~mm}$ ). These are the geometrical conditions found either with an initially larger head, or with functional swelling of the cartilage in a primarily congruous joint. The final model, model 5 (Fig. 6 a) is a combination of the head from model 4 with the deeper socket of model $3\left(x^{\mathrm{k}}=y^{\mathrm{k}}=10.1 \mathrm{~mm}, y^{\mathrm{p}}=10.25 \mathrm{~mm}\right.$, a
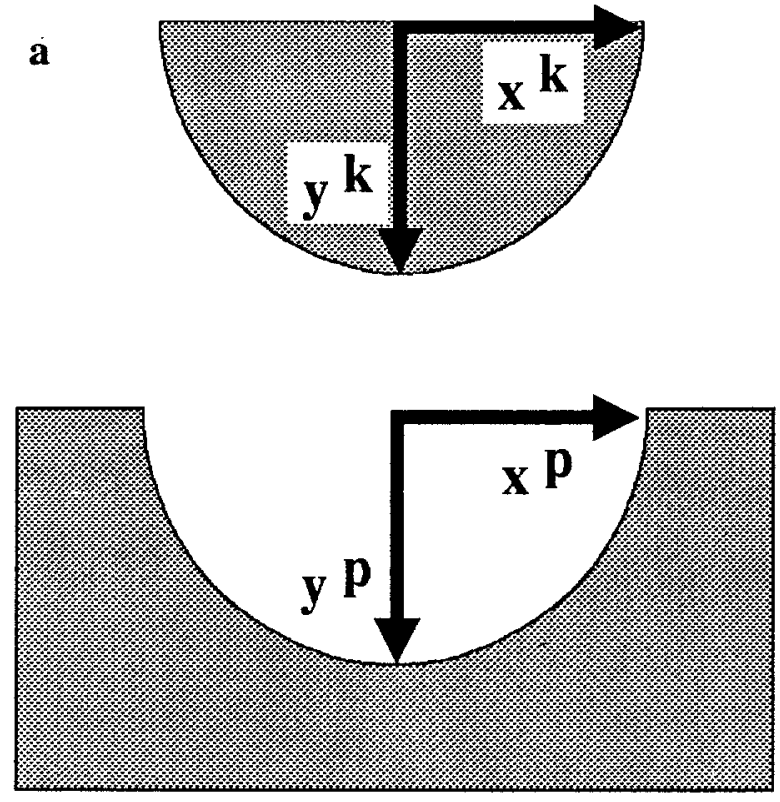

b

$0-5 \mathrm{~N} / \mathrm{mm}^{2}$
$5-10 \mathrm{~N} / \mathrm{mm}^{2}$
$10-15 \mathrm{~N} / \mathrm{mm}^{2}$
$15-20 \mathrm{~N} / \mathrm{mm}^{2}$
$20-25 \mathrm{~N} / \mathrm{mm}^{2}$
$25-30 \mathrm{~N} / \mathrm{mm}^{2}$
$30-35 \mathrm{~N} / \mathrm{mm}^{2}$
$35-40 \mathrm{~N} / \mathrm{mm}^{2}$
$40-45 \mathrm{~N} / \mathrm{mm}^{2}$
$45-50 \mathrm{~N} / \mathrm{mm}^{2}$
$>50 \mathrm{~N} / \mathrm{mm}^{2}$

Fig. 1. a Basic geometry of the five models. b"Grey value legends" of the equivalent stress (von Mises)

$x^{p}=10.0 \mathrm{~mm}$ ). This represents the conditions obtained in a joint with a deeper socket either for an initially larger head, or in which functional swelling of the cartilage has occurred in the presence of primary incongruity.

The calculations were carried out by the program Marc (Marc Research Corporation, Palo Alto, Calif., USA). The five geometrical patterns were built up as axisymmetrical models (Zienkiewicz and Taylor 1989) with variable contact areas. The head of the joint was considered to be a rigid body, not subject to deformation, which is by degrees pressed into the socket - the deformable component. The stress distribution was calculated for axial loads of 100,600 , 3700 and $6900 \mathrm{~N}$. This roughly corresponds to loading the joint with $1 / 6,1,6$ and 11.5 times the weight of the body. The base of the socket was fixed along the $x$ and $y$ axes. Anisotropy and viscoelasticity of the material were not considered. In accordance with the results reported by Brown and Vrahas (1984) for subchondral bone, 

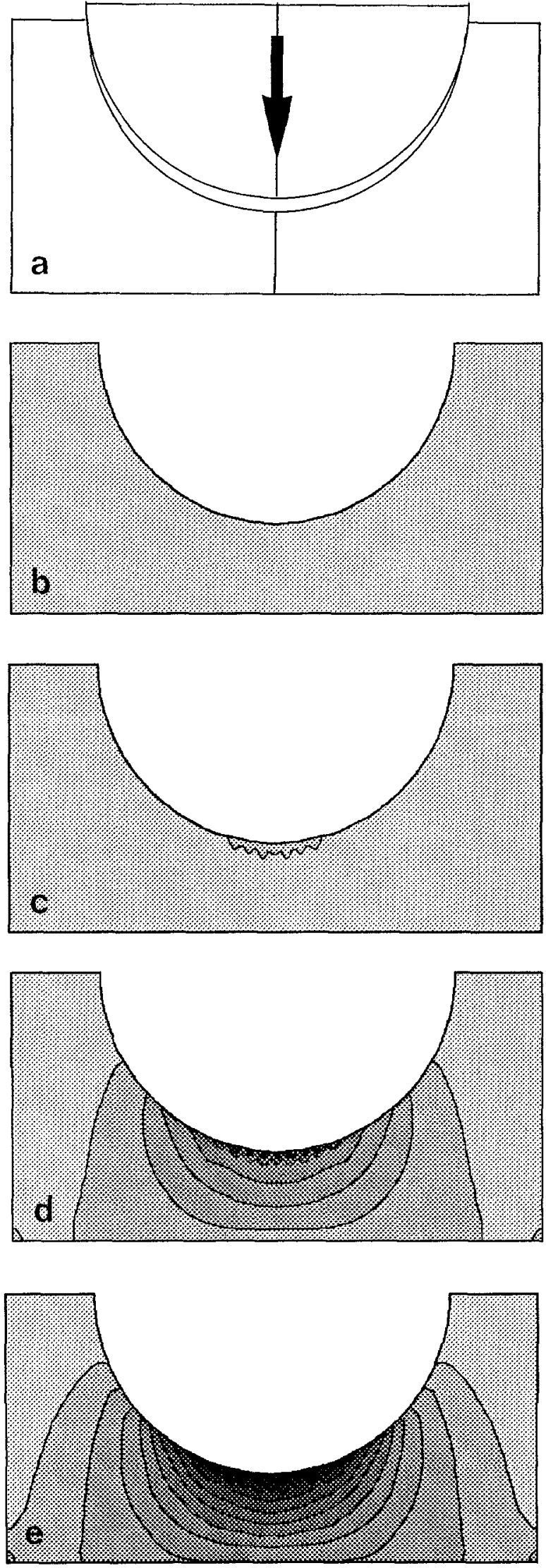

Fig. 2. a Schematic drawing of the geometrical set-up of model 1 (congruous head and socket of the joint). b-e Distribution of the von Mises stress in model 1 (340 elements, 385 nodes, 710 degrees of freedom) under various loads. b $100 \mathrm{~N}$ (max. equiv. stress 3.2 $\left.\mathrm{N} / \mathrm{mm}^{2}\right)$. c $600 \mathrm{~N}\left(\max\right.$. equiv. stress $\left.9.6 \mathrm{~N} / \mathrm{mm}^{2}\right)$. d $3700 \mathrm{~N}(\max$. equiv. stress $39.2 \mathrm{~N} / \mathrm{mm}^{2}$ ). e $6900 \mathrm{~N}$ (max. equiv. stress $61.5 \mathrm{~N} / \mathrm{mm}^{2}$ )
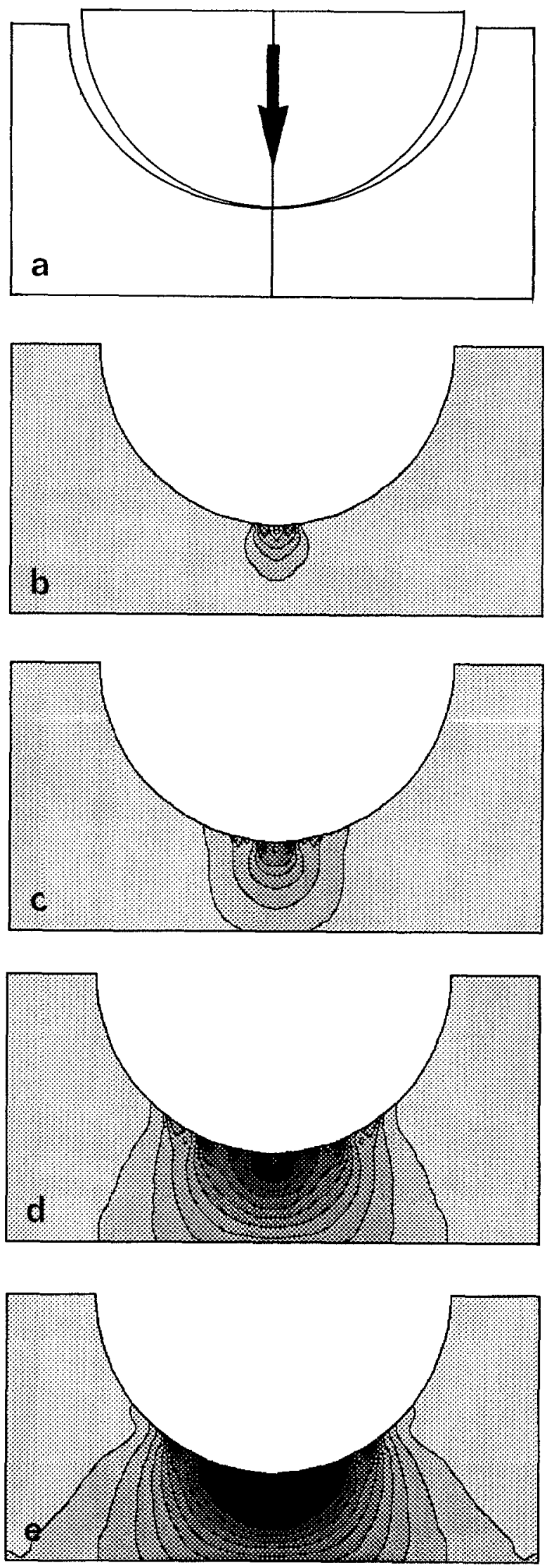

Fig. 3. a Schematic (exaggerated) drawing of the geometrical set-up of model 2, (flatter socket). b-e Distribution of the von Mises stress in model 2 (340 elements, 385 nodes, 710 degrees of freedom) under various loads; b $100 \mathrm{~N}$ (max. equiv. stress $37.1 \mathrm{~N} / \mathrm{mm}^{2}$ ). c $600 \mathrm{~N}$ (max. equiv. stress $43.4 \mathrm{~N} / \mathrm{mm}^{2}$ ). d $3700 \mathrm{~N}$ (max. equiv. stress 73.2 $\mathrm{N} / \mathrm{mm}^{2}$ ). e $6900 \mathrm{~N}$ ( $\max$. equiv. stress $101.3 \mathrm{~N} / \mathrm{mm}^{2}$ ) 

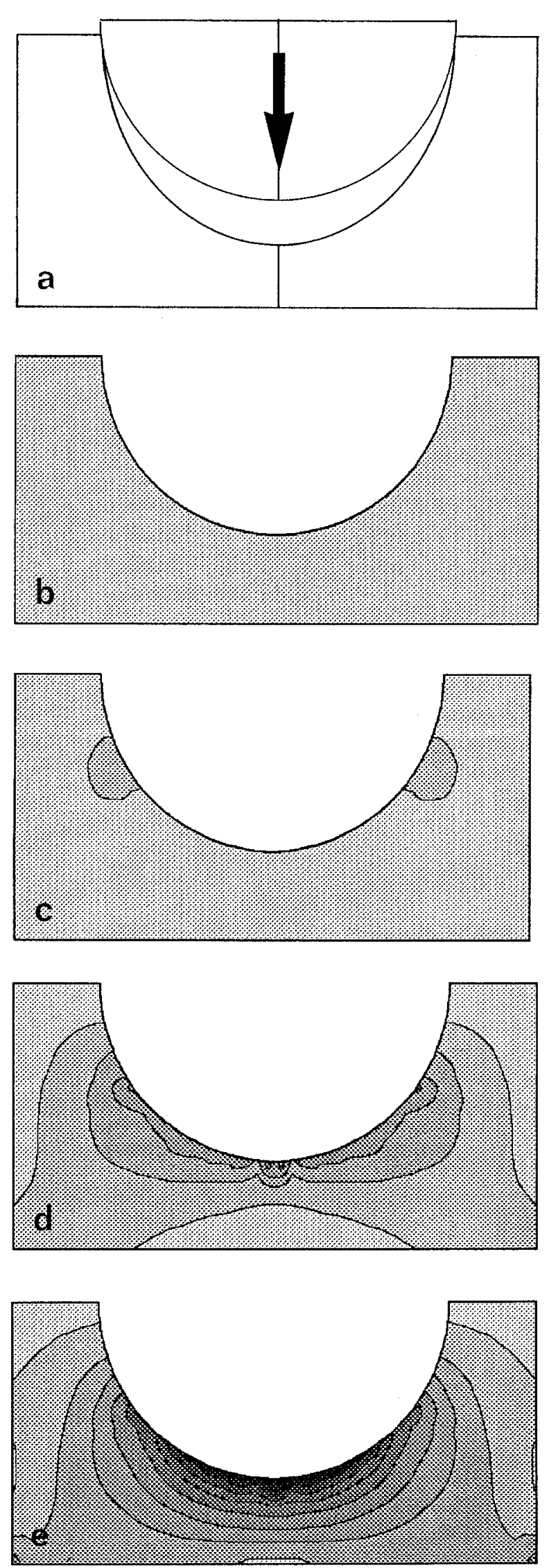

Fig. 4. a Schematic (exaggerated) drawing of the geometrical set-up of model 3, (deeper socket). b-e Distribution of the von Mises stress in model 3 (310 elements, 352 nodes, 670 degrees of freedom) under various loads. b $100 \mathrm{~N}$ (max. equiv. stress $1.9 \mathrm{~N} / \mathrm{mm}^{2}$ ). c $600 \mathrm{~N}$ (max. equiv. stress $9.3 \mathrm{~N} / \mathrm{mm}^{2}$ ). d $3700 \mathrm{~N}$ (max. equiv. stress $23.8 \mathrm{~N} / \mathrm{mm}^{2}$ ). e $6900 \mathrm{~N}\left(\max\right.$. equiv. stress $\left.53.0 \mathrm{~N} / \mathrm{mm}^{2}\right)$
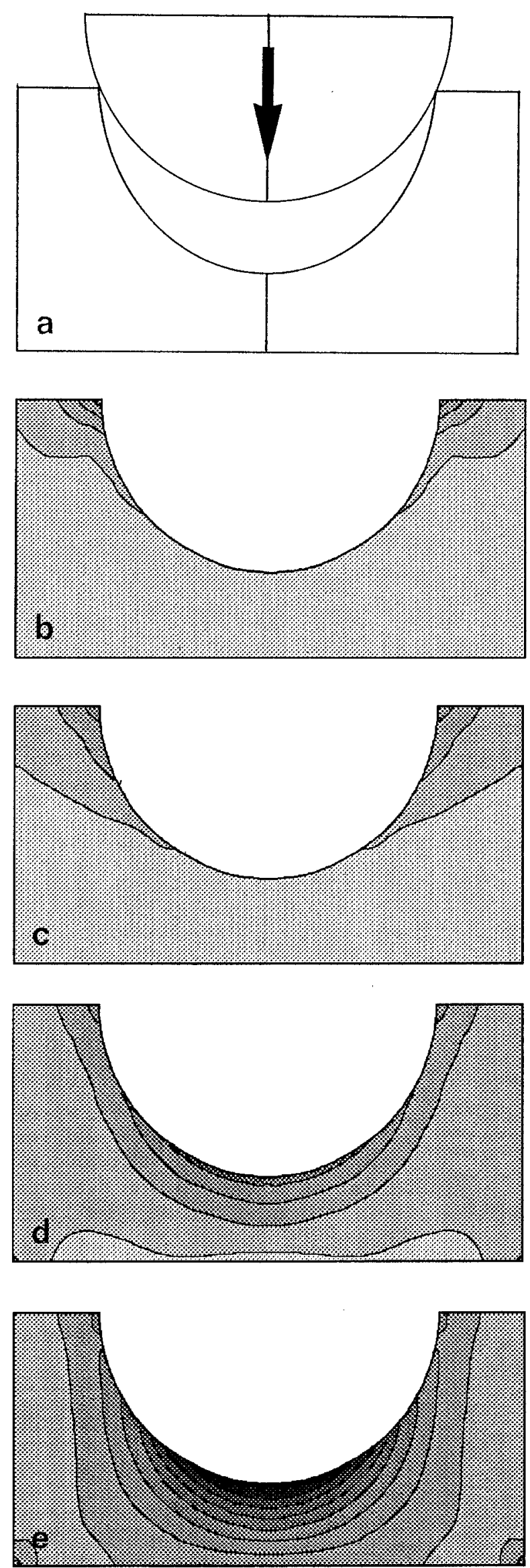

Fig. 5. a Schematic (exaggerated) drawing of the geometrical set-up of model 4, (oversized head). b-e Distribution of the von Mises stress in model 4 (300 elements, 341 nodes, 635 degrees of freedom) under various loads. b $100 \mathrm{~N}$ (max. equiv. stress $21.6 \mathrm{~N} / \mathrm{mm}^{2}$ ). c 600 $\mathrm{N}$ (max. equiv. stress $17.4 \mathrm{~N} / \mathrm{mm}^{2}$ ). d $3700 \mathrm{~N}$ (max. equiv. stress 21.8 $\left.\mathrm{N} / \mathrm{mm}^{2}\right)$. e $6900 \mathrm{~N}\left(\max\right.$. equiv. stress $\left.45.9 \mathrm{~N} / \mathrm{mm}^{2}\right)$ 

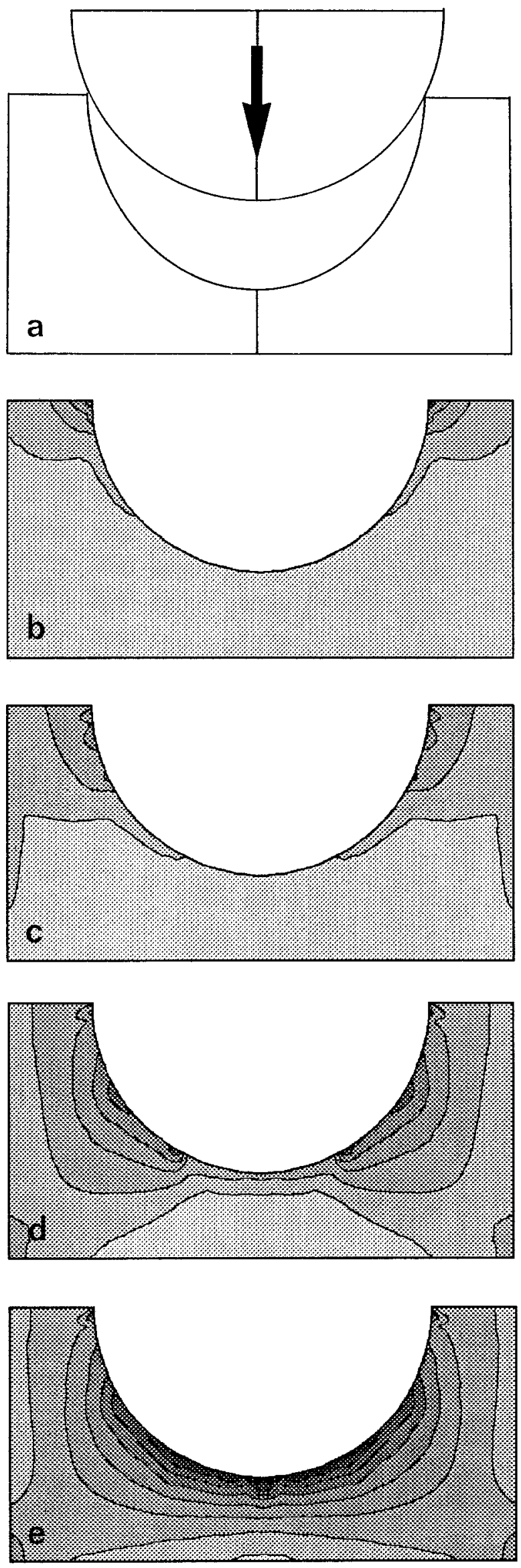

Table 1. Maximum values of the equivalent stress (von Mises) in relationship to the load applied (values in $\mathrm{N} / \mathrm{mm}^{2}$ )

\begin{tabular}{lrrlc}
\hline Model & $100 \mathrm{~N}$ & $600 \mathrm{~N}$ & $3700 \mathrm{~N}$ & $6900 \mathrm{~N}$ \\
\hline No. 1 & 3.2 & 9.6 & 39.2 & 61.5 \\
No. 2 & 37.1 & 43.4 & 73.2 & 101.3 \\
No. 3 & 1.9 & 9.3 & 23.8 & 53.0 \\
No. 4 & 21.6 & 17.4 & 21.8 & 45.9 \\
No. 5 & 21.8 & 19.4 & 29.3 & 43.2 \\
\hline
\end{tabular}

the modulus of elasticity was taken to be $1500 \mathrm{~N} / \mathrm{mm} 2$. This value is also valid for the average density of cancellous bone $\left(0.8 \mathrm{~g} / \mathrm{cm}^{3}\right.$, Carter and Hayes 1977). Cortex and articular cartilage were not treated separately. The Poisson number was accepted as 0.33 (Knauss 1980; Rohlmann et al. 1983), and the coefficient of friction between head and socket as 0 (Carter et al. 1987 a). The calculation was carried out with the large displacement model; that is to say, secondary effects due to deformation (developing or changing moments) were taken into account. The results were expressed as "von Mises" stresses (Fig. 1 b), that is to say equivalent stresses (or stress intensity) calculated from the values for normal (tension and pressure) and shear stresses. The models consisted of 300 to 340 elements, 341 to 385 nodes and 635 to 710 degrees of freedom.

\section{Results}

Under forces of 600, 3700 and $6900 \mathrm{~N}$, model 1 (Fig. 2 a) shows in each case an increasing equivalent stress from the periphery to the centre of the socket (Fig. 2 b). Peripherally no von Mises stress is active, even with the higher loads. Under a force of $100 \mathrm{~N}$, a stress intensity of 3.2 $\mathrm{N} / \mathrm{mm}^{2}$ is reached in the centre of the socket, and with a force of $6900 \mathrm{~N}, 61.5 \mathrm{~N} / \mathrm{mm}^{2}$ (Table 1).

In model 2 (Fig. 3 a), with a flatter socket, a significantly higher stress intensity is calculated for each load than in the congruous model (Table 1), and the maxima are always to be found in the depths of the socket (Fig. 3 b).

In model 3 (Fig. 4 a, deeper socket) significant equivalent stresses appear under less loading in a region about $30^{\circ}$ from the inlet of the socket (Fig. 4 b). Only with higher values does the centre of the socket begin to share in the transmission of force, the highest values being reached there under a load of $6900 \mathrm{~N}$. The maximum von Mises stresses are found under all loading conditions to be lower than in the congruous model (Table 1).

With model 4 (Fig. 5 a, oversized head), the equivalent stresses are built up under slight loading at the periphery (Fig. $5 \mathrm{~b}$ ). They move towards the centre of the socket as the load increases. Under 100 and $600 \mathrm{~N}$ the maximum stress intensity lies above the values in models 1 and 3,

Fig. 6. a Schematic (exaggerated) drawing of the geometrical set-up of model 5, (oversized head combined with deeper socket). b-e Distribution of the von Mises stress in model 5 (310 elements, 352 nodes, 670 degrees of freedom) under various loads. b $100 \mathrm{~N}$ (max. equiv. stress $21.8 \mathrm{~N} / \mathrm{mm}^{2}$ ). c $600 \mathrm{~N}$ (max. equiv. stress $19.4 \mathrm{~N} / \mathrm{mm}^{2}$ ). d $3700 \mathrm{~N}$ (max. equiv. stress $29.3 \mathrm{~N} / \mathrm{mm}^{2}$ ). e $6900 \mathrm{~N}$ (max. equiv. stress $\left.43.2 \mathrm{~N} / \mathrm{mm}^{2}\right)$ 
but with loads of 3700 and $6900 \mathrm{~N}$ they are lower (Table 1).

With model 5 (Fig. 6 a, deeper socket combined with oversized head), the stress is also built up from the periphery towards the centre (Fig. 6 b). With loads of moderate value, the highest stress intensity is found between the periphery and centre of the socket. Even under higher forces, the equivalent stress remains distributed relatively constantly over the inner $2 / 3$ of the socket. In comparison with the other geometrical patterns, $6900 \mathrm{~N}$ produced in this model the lowest maximum von Mises stresses (Table 1).

\section{Discussion}

\section{Method}

The intention of the present work was to examine the principal influence of geometric factors on the stress distribution in joints. The distribution of the equivalent stress and the level of stress intensity under increasing loads were investigated. Since quantitative data on the exact geometry of the joints are not yet available, five comparative models were built up from the observed qualitative anatomical facts. For the time being, the possible effects of anisotropy and viscoelasticity have been ignored. Furthermore, the models were based on the assumption that the material is homogeneously distributed, although the material properties of cortical bone and articular cartilage differ from those of cancellous or subchondral bone (for full bibliography see Schröder and Gall 1992). In addition to this, the density values vary considerably within the spongiosa and in the subchondral region. This variation in subchondral bone density is found within as well as between individuals (Eckstein et al. 1992; Müller-Gerbl et al. 1992). Investigations with the finite element method by Hayes et al. (1982) and Merz (1993) have shown that inhomogeneous material properties influence the stress distribution in the tissues. The models suggested here are, however, not intended to allow realistic quantitative statements on stress intensity in the joint to be made. For this to be possible it would be necessary to take into account the exact distribution of the thickness of the cartilage (Mockenhaupt 1990), as well as the inhomogeneity of the elastic properties of bone. The models are supposed to isolate the influence of the geometrical parameters on the stress distribution, and for this the assumption of homogeneous physical properties in order to make comparative estimates would seem to be both sufficient and reasonable.

\section{Results}

The models have shown that very slight variations in the geometry of the articular surfaces can have a profound effect on the stress distribution in joints. As Kummer (1968), Kummer et al. (1987) and Mockenhaupt (1990) have remarked, a geometrically congruous joint does not permit equal distribution of the stress, since only those partial vectors running parallel to the resultant force can be transmitted through the joint surface. In the case of a ball-and-socket joint, or a hinge joint with a large amount of surrounding bone, this leads to a "bellshaped" stress distribution with peak values in the depths of the socket, falling off to zero peripherally.

The facts that less satisfactory relationships are obtained by modelling a flatter socket, and that the stress peaks arising in its depths significantly exceed the values in all other cases, agree well with the photoelastic findings reported by Kempson et al. (1971) and Tillmann (1978). These results are plausible, since the corresponding force is transmitted by smaller, centrally localized load-bearing areas. The distribution pattern of the subchondral mineralization in the radiohumeral joint (central density maximum Eckstein et al 1993 a), also confirms this result, since the subchondral bone density has been shown to reflect the long-term stress acting during physiological use of a joint (Pauwels 1963, 1980). The less satisfactory mechanical situation in the radiohumeral joint may, among other things, contribute to the fact that osteoarthrotic changes more commonly attack this part of the elbowjoint than the humero-ulnar component (Goodfellow and Bullough 1967).

On the other hand, the model with a deeper socket anticipates a better relationship for the stress distribution as postulated by Bullough (1981) and Greenwald (1991). As seen in vertical section through the joint, the force is transmitted by two centres. A corresponding geometrical pattern has been found in the case of the hipjoint (Walmsley 1928; Bullough et al. 1968, 1973; Greenwald and O'Connor 1971; Goodfellow and Mitsou 1977; Rushfeldt and Mann 1979; Afoke et al. 1980; Miyanaga et al. 1984; Löhe et al. 1993), the anklejoint (Riede et al. 1971; Wynarsky and Greenwald 1983) and also the humero-ulnar joint (Bullough and Jagannath 1983; Eckstein at al. 1993 c). Interestingly enough, the highest stress values in this model under average loading are found in those regions of the articular surface where the highest density values are measured by X-ray densitometry (Tillmann 1971, 1978) and CT osteoabsorptiometry (Müller-Gerbl et al. 1993; Müller-Gerbl and Putz 1993; Eckstein et al 1993 a, b). It is hence entirely possible to trace back bicentric distribution patterns of the subchondral bone density to geometrical factors; that is to say, to incongruity due to a deeper socket. Bullough et al. (1968) were able to show that with increasing age the geometry of the hipjoint is subject to change, i.e. the articular surfaces become more congruous. This is also supported by a corresponding change from bicentric to monocentric in the mineralization pattern of the facies lunata (Müller-Gerbl et al. 1993). The results obtained from our models also suggest that the development of osteoarthrosis in the roof of the hipjoint socket (Bullough et al. 1973; Tillmann 1973, 1978) may, apart from other causes, be due to an age change in the geometrical pattern of the joint.

The assumption of an initially enlarged head or functional swelling of cartilage (Oberländer et al. 1984) implies that in the model the force will be transmitted through the outermost periphery of the joint also. The development of stress at lower loads begins here, and this 
physical activity of the subject, (cyclic loading of the joint)

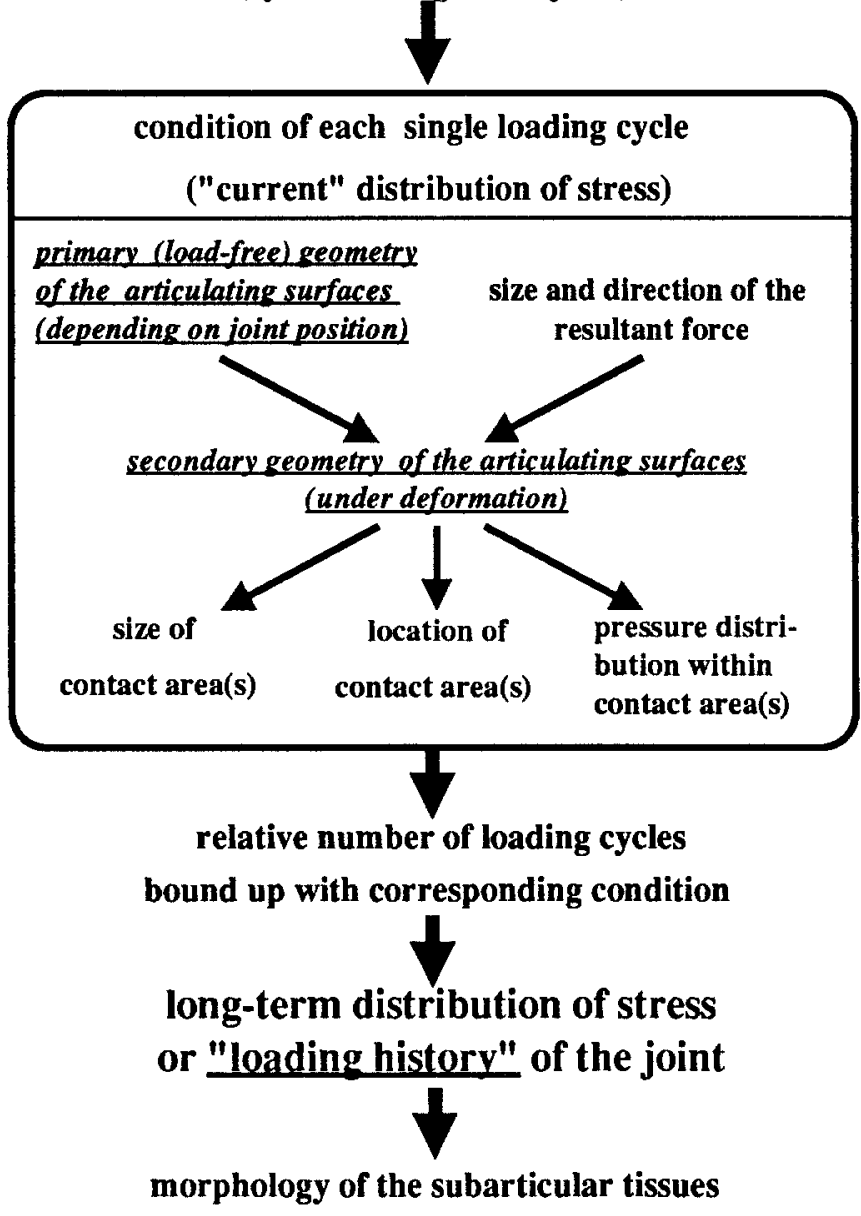

Fig. 7. Interplay of the factors that determine the "loading history" of a joint

region continues to play a part in the transmission of force under higher loading. This finally leads to a very satisfactory distribution of the stress. If there is also a primary incongruity due to a deeper socket, the enlargement of the head will again provide a more advantageous distribution of the stress. Even with higher loads, the stress is distributed more equally over a wide area of the socket, which is why the lowest peak values are found in this model.

It is true that with cyclic loading of the joint, the primary (that is to say, load-free) geometrical shape of the articulating components is a deciding factor for the actual and long-term distribution of stress in the joint (Fig. 7).

As far as the subchondral bone is concerned, an inhomogeneous distribution of the density (dependent upon the shape of each joint, e.g. bicentric or monocentric), can be predicted. This is because the "remodelling" (Carter 1984; Carter et al. 1987, 1991) of the subchondral bone of a joint is determined by the long-term mechanical stress ("loading history") acting on its component tissues (Eckstein et al. 1992, 1993 a, b; Müller-Gerbl et al. 1992, 1993).

It may be assumed that the geometric pattern of the joint described will have a profound effect upon the nutritive situation of the articular cartilage as well. Models 1 and 2 suggest that the cyclic action of force will produce no stress at all on the cartilage at the periphery of the socket, but a considerable degree of high, quasi "static" stress on the cartilage lying in its depths. As against this, the shifting of the load-bearing areas from the periphery inwards under cyclic loading suggested by model 3 , and particularly by models 4 and 5 , distributes a more "dynamic" load over all regions of the cartilage. Such conditions, i.e. intermittent stimulation, have been experimentally proved to activate cartilage metabolism (Sah et al. 1989). An advantageous effect on the articular cartilage has also been confirmed clinically (Salter at al. 1980; O' Driscoll et al. 1988). On the other hand, static stress is considered to have an adverse action on the synthetic activity of cartilage cells (Jones et al. 1982; Gray et al. 1988; Sah et al. 1989), and after a time even to cause damage to the tissue (Salter and Field 1960; Trias 1961). Furthermore, shifting of the load-bearing areas within the joint is likely to promote circulation of the nutrient synovial fluid (Bullough 1981) and an increased exchange with the fluid bound in the cartilage (Putz and Fischer 1993). Load-dependent deformation of the cartilage may also contribute to lubrication of the articular surfaces and a reduction of the coefficient of friction of the articular cartilage (Lewis and McCutchen 1959).

We conclude from these results that the incongruity described may be regarded as a functionally active and biologically advantageous principle, which allows a more equal distribution of the stress throughout the joint and improves the nutritive situation of the cartilage. The term "incongruity" must therefore not be automatically equated with "prearthrotic deformity" (Hackenbroch 1943), as it is sometimes done in routine clinical work.

With future models on the force transmission in joints it will be necessary to calculate the stresses in terms of the geometry of the articular components, if realistic values are to be obtained. To make quantitatively accurate pronouncements on the stress distribution, it will be necessary to carry out further investigations, and to go into the exact morphology of the articular surfaces and the subarticular tissues.

Acknowledgements. We should like to express our thanks to Claudia Dinter and Horst Ruß for their great help in preparing the illustrations, to Professor Dr. P. Niederer of the Institut für Biomedizinische Technik und Medizinische Informatik der ETH, Zürich, for his kindness in lending us the hard- and software and to Dr. Francis Steel for translating the manuscript.

\section{References}

Afoke NYW, Byers PD, Hutton WC (1980) The incongruous hip joint: a casting study. J Bone Joint Surg 62 B:511-514

Bünck S (1990) Krümmungs- und Kontaktflächenverhältnisse der Articulatio humeroradialis. Anat Anz 171:45-53

Bullough PG (1981) The geometry of diarthrodial joints, its physiological maintenance, and the possible significance of age-related changes in geometry-to-load distribution and the developement of osteoarthritis. Clin Orthop 156:61-66

Bullough PG, Jagannath A (1983) The morphology of the calcification front in articular cartilage. J Bone Joint Surg 65 B:72-78

Bullough P, Goodfellow J, Greenwald AS, O' Connor S (1968) Incongruent surfaces in the human hip joint. Nature 217:1290 
Bullough P, Goodfellow J, O' Connor J (1973) The relationship between degenerative changes and load bearing in the human hip. $\mathrm{J}$ Bone Joint Surg 55 B:746-758

Brown TD, Vrahas MS (1984) The apparent elastic modulus of the juxtarticular subchondral bone of the femoral head. J Orthop Res 2: 32-38

Carter DR (1984) Mechanical loading histories and cortical bone remodeling. Calcif Tissue Int 36:519-524

Carter DR, Hayes WC (1977) The compressive behaviour of bone as a two-phased porous structure. J Bone Joint Surg 59 A:954 962

Carter DR, Rapperport DJ, Fyhrie DP, Schurmann DJ (1987 a) Relation of coxarthrosis to stresses and morphogenesis - a finite element analysis. Acta Orthop Scand 58:611-619

Carter DR, Orr TE, Fyhrie DP (1987 b) Relationship between loading history and femoral cancellous bone architecture. J Biomech 22: 231-244

Carter DR, Wong M, Orr TE (1991) Musculoskeletal ontogeny, phylogeny, and functional adaptation. J Biomech 24:3-16

Day WH, Swanson SAV, Fremann MAR (1975) Contact pressures in the loaded human cadaver hip. J Bone Joint Surg 57B:302-313

Eckstein F, Müller-Gerbl M, Putz R (1992) Distribution of subchondral bone density and cartilage thickness in the human patella. J Anat 180:425-433

Eckstein F, Steinlechner M, Müller-Gerbl M, Putz R (1993 a) Mechanische Beanspruchung und subchondrale Mineralisierung des menschlichen Ellbogengelenks - eine CT-osteoabsorptiometrische Studie. Unfallchirurg 96:99-104

Eckstein F, Löhe F, Steinlechner M, Müller-Gerbl M, Putz R (1993 b) Kontaktflächen des menschlichen Humeroulnargelenks in Abhängigkeit von der Anpreßkraft - ihr Zusammenhang mit subchondraler Mineralisierung und Gelenkflächenmorphologie der Incisura trochlearis. Ann Anat 175:545-552

Eckstein F, Löhe F, Schulte E, Müller-Gerbl M, Milz S, Putz R (1993 c) Physiological incongruity of the humero-ulnar joint: - a functional principle of optimized stress distribution acting upon articulating surfaces. Anat Embryol 188:449-455

Goodfellow JW, Bullough PG (1967) The pattern of aging of the articular cartilage of the elbow joint. J Bone Joint Surg 49 B:174-181

Goodfellow JW, Mitsou A (1977) Joint surface incongruity and its maintenance. J Bone Joint Surg 59B:446-451

Gray ML, Pizzanelli AM, Grodzinsky AJ, Lee RC (1988) Mechanical and physicochemical determinants of the chondrocyte biosynthetic response. J Orthop Res 6:777-792

Greenwald AS (1991) Biomechanics of the hip. In: Steinberg ME (ed) The hip and its disorders. Saunders, Philadelphia, pp 47-56

Greenwald AS, O' Connor JJ (1971) The transmission of load through the human hip joint. J Biomech 4:507-528

Hackenbroch M (1943) Die Arthrosis deformans der Hüfte. Thieme, Leipzig

Hayes WC, Snyder B, Levine BM, Ramaswamy S (1982) Stress - morphology relationships in trabecular bone of the patella. In: Gallgher RH, Simon BR, Johnson PC, Gross JF (eds) Finite elements in biomechics. Wiley, Chichester

Huiskes R, Chao EYS (1983) A survey of finite element analysis in orthopedic biomechanics: the first decade. J Biomech 16:385 409

Ingelmark BE, Ekholm R (1948) A study on variations in the thickness of articular cartilage in association with rest and periodical load. Acta Soc Med Upsalien 53:61-74

Jones IL, Klamfeldt DDS, Sandstrom T (1982) The effect of continuous mechanical pressure upon the turnover of articular cartilage proteoglycans in vitro. Clin Orthop 165:283-289

Kempson GE, Spivey CJ, Swanson SAV, Freeman AR (1971) Patterns of cartilage stiffness on normal and degenerate human femoral heads. J Biomech 4:597-609

Knauss P (1981) Materialkennwerte und Festigkeitsverhalten des spongiösen Knochengewebes am coxalen Human-Femur. Biomed Tech (Berlin) 26:200-210

Kummer B (1968) Die Beanspruchung des menschlichen Hüftgelenks. 1. Allgemeine Problematik. Z Anat Entwicklungsgesch 127:277-285

Kummer B, Breul R, Stauss M, Lohscheidt K (1987) Spannungsverteilung über Kugelgelenkflächen. Verh Anat Ges 81:445-446

Lewis PR, McCutchen CW (1959) Experimental evidence for weeping lubrication in mammalian joints. Nature 184:1285

Löhe F, Eckstein F, Putz R (1993) Dehnung des Lig. transversum acetabuli. Unfallchirurg (in press)

Merz BR (1993) Finite Elemente-Analyse von exzidierten Femora basierend auf der quantitativen Computer Tomographie. Dissertation, ETH Zürich
Miyanaga Y, Fukubayashi T, Kurosawa H (1984) Contact study of the hip joint. Arch Orthop Trauma Surg 103:13-17

Mockenhaupt J (1990) Pressure distribution in partly contacting joints a computerized simulation model. Anat Anz 171:313-321

Müller-Gerbl M, Putz R (1993) Zur Morphologie und Mechanik der Gelenke in Abhängigkeit vom Lebensalter. In: Pesch HJ, Stöß H, Kummer B (eds) Osteologie aktuell VII. Springer Berlin Heidelberg New York, pp 38-41

Müller-Gerbl M, Putz R, Kenn R (1992) Demonstration of subchondral bone density patterns by three dimensional CT osteoabsorptiometry as a noninvasive method for in vivo assessment of individual longterm stresses in joints. J Bone Miner Res 7 [Suppl 2]:411-418

Müller-Gerbl M, Putz R, Kenn R, Kierse R (1993) People in different age groups show different hip joint morphology. Clin Biomech 8: 66-72

Oberländer W, Breul R, Kurrat HJ (1984) Die Querfurche des Ellbogengelenkes. Eine biomechanische Deutung ihrer Entstehung. Z Orthop 122:623-742

O'Driscoll SW, Keeley FW, Salter RB (1988) Durability of regenerated articular cartilage produced by free autogenous periostal grafts in major full thickness defects in joint surfaces under the influence of continuous passive motion: a follow up at one year. J Bone Joint Surg 70A:595-606

Orr JF (1992) Two and three dimensional photoelastic techniques. In: Miles AW, Tanner KE (eds) Strain measurement biomechanics. Chapmann, London

Pauwels F (1963) Die Druckverteilung im Ellbogengelenk, nebst grundsätzlichen Bemerkungen über den Gelenkdruck. 11. Beitrag zur funktionellen Anatomie und kausalen Morphologie des Stützapparates. Z Anat Entwicklugnsgesch 123:643-667

Pauwels F (1980) Biomechanics of the locomotor apparatus. Springer, Berlin Heidelberg New York

Putz R, Fischer H (1993) Altersunterschiede der Anordnung der kollagenen Fasern im Gelenkknorpel. In: Pesch HJ, Stöß H, Kummer B (eds) Osteologie aktuell 7. Springer, Berlin Heidelberg New York, pp 42-44

Rapperport DJ, Carter DR, Schurmann DJ (1985) Contact finite element stress analysis of the hip joint. J Orthop Res $3: 435446$

Riede UN, Heitz P, Ruedi T (1971) Gelenkmechanische Untersuchungen zum Problem der posttraumatischen Arthrosen im oberen Sprunggelenk. 2. Einfluß der Talusform auf die Biomechanik des oberen Sprunggelenks. Langenbecks Arch Chir 330:174-184

Rohlmann A, Mössner U, Bergmann G (1983) Finite-element-analysis and experimental investigation in a femur with hip endoprothesis. J Biomech 16:727-742

Rushfeldt PD, Mann RW (1979) Influence of cartilage geometry on the pressure distribution in the human hip joint. Science 204: 413-415

Sah RLY, Kim YJ, Doong JYH, Grodzinsky AJ, Plaas AHK, Sandy JD (1989) Biosynthetic response of cartilage explants to dynamic compression. J Orthop Res 7:619-636

Salter RB, Field P (1960) The effects of continuous compression on living articular cartilage. J Bone Joint Surg 42A: 31-49

Salter RB, Simmonds DF, Malcolm BW, Rumble EJ, Mac-Michael D, Clements ND (1980) The biological effect of continuous passive motion on the healing of full-thickness defects in articular cartilage. J Bone Joint Surg 62 A:1232-1251

Schröder DW, Gall H (1992) Zum biomechanischen Einfluß der Synovialflüssigkeit auf die Funktion der Gelenke. Zuckerschwerdt, München

Soslowsky LJ, Flatow EL, Bigliani LU, Pawluk RJ, Ateshian GA, Mow VC (1992) Quantitation of in situ contact areas at the glenohumeral joint: a biomechanical study. J Orthop Res 10:524-534

Tillmann B (1971)Die Beanspruchung des menschlichen Ellenbogengelenkes. 1. Funktionelle Morphologie der Gelenkflächen. Z Anat Entwicklungsesch 134:328-342

Tillmann B (1973b) Zur Lokalisation von degenerativen Veränderungen am Femurkopf bei der Coxarthrose. Z Orthop 111:23-27

Tillmann B (1978) A contribution to the functional morphology of articular surfaces. Thieme, Stuttgart

Trias A (1961) Effect of persistent pressure on the articular cartilage. An experimental study. J Bone Joint Surg 43B: 376-386

Walmsley T (1928) Articular mechanics of the diarthroses. J Bone Joint Surg $10 \mathrm{~B}: 40-45$

Wynarsky GT, Greenwald AS (1983) Mathematical model of the human ankle joint. J Biomech 16:241-251

Zienkiewicz OC, Taylor RL (1989) The finite element method, 4th edn, vol 1. Basic formulation and linear problems. McGraw Hill, London 